\title{
Blood Pressure, Proteinuria, and Phosphate as Risk Factors for Progressive Kidney Disease: A Hypothesis
}

\author{
Mario Cozzolino, MD, $P h D,{ }^{1 *}$ Giorgio Gentile, $M D, P h D,{ }^{2,3 *}$ Sandro Mazzaferro, $M D,{ }^{4}$ \\ Diego Brancaccio, $M D,{ }^{5}$ Piero Ruggenenti, $M D,{ }^{2,3}$ and \\ Giuseppe Remuzzi, MD, FRCP ${ }^{2,3}$
}

\begin{abstract}
Chronic kidney disease (CKD) affects approximately 500 million people worldwide and is increasingly common in both industrialized and emerging countries. Although the mechanisms underlying the inexorable progression of CKD are incompletely defined, recent discoveries may pave the way to a more comprehensive understanding of the pathophysiology of CKD progression and the development of new therapeutic strategies. In particular, there is accumulating evidence indicating a key role for the complex and yet incompletely understood system of divalent cation regulation, which includes phosphate metabolism and the recently discovered fibroblast growth factor 23 (FGF-23)/klotho system, which seems inextricably associated with vitamin $\mathrm{D}$ deficiency. The aim of this review is to discuss the links between high blood pressure, proteinuria, phosphate levels, and CKD progression and explore new therapeutic strategies to win the fight against CKD. Am J Kidney Dis. xx(x):xxx. (c) 2013 by the National Kidney Foundation, Inc.
\end{abstract}

INDEX WORDS: Chronic kidney disease; vitamin D deficiency; blood pressure; proteinuria; phosphate.

$\mathbf{C}$ hronic kidney disease (CKD) is a silent killer. Four of 5 people with advanced CKD are not aware of the disease until death is imminent and kidney replacement therapy (dialysis or kidney transplantation) is unavoidable. Unfortunately, $<10 \%$ of people requiring replacement therapy have access to it, and more than 1 million people worldwide die of untreated kidney failure each year because dialysis or kidney transplantation is unaffordable in most countries. This represents a huge economic burden, with global costs from 2000-2010 surpassing $\$ 1$ trillion. ${ }^{1,2}$

Worsening kidney function is associated with a marked increase in cardiovascular morbidity and mortality ${ }^{1,3}$ independent of other risk factors. Coexistent hypertension is present in $\sim 80 \%$ of patients with CKD and worsens cardiovascular outcomes because only $64 \%$ of patients with CKD achieve adequate blood pressure control. ${ }^{4}$ As a consequence, only a minority of the hundreds of thousands of patients with stages 3 and 4 CKD reach kidney failure. ${ }^{5}$ Proteinuria also is an important prognostic factor in patients with CKD. Although patients with nonproteinuric CKD are at greater risk of cardiovascular mortality than progression to kidney failure, the opposite may be true for the presence of proteinuria. Patients from the REIN (Ramipril Efficacy in Nephropathy) Study who were in the highest tertile of baseline proteinuria (protein excretion $\geq 3.8 \mathrm{~g} / \mathrm{d}$ ) also experienced the highest rate of glomerular filtration rate (GFR) loss during followup. ${ }^{6}$

In addition, although post hoc analysis of RENAAL (Reduction of Endpoints in NIDDM [Non-InsulinDependent Diabetes Mellitus] With the Angiotensin II Antagonist Losartan) showed that $85 \%$ of patients with proteinuria with protein excretion $\geq 3 \mathrm{~g} / \mathrm{d}$ reached the composite end point of doubling of serum creatinine level or end-stage renal disease (ESRD), only $44 \%$ of these patients reached the composite cardiovascular outcome. $^{7}$

Besides the well-established role of hypertension and proteinuria in the progression of CKD, accumulating evidence indicates a key role for the complex and incompletely understood system of divalent cation regulation, which includes phosphate metabolism and the recently discovered fibroblast growth factor 23 (FGF-23)/klotho system, which seems inextricably associated with vitamin $\mathrm{D}$ deficiency.

The aim of this review article is to emphasize the links between 2 traditional factors of CKD progression, blood pressure and proteinuria (here identified as the first 2 "P" factors for progression), and the more recent subject of phosphate (the third "P" for progres-

From the ${ }^{I}$ Department of Health Sciences, University of Milan, Renal Division, San Paolo Hospital, Milan; ${ }^{2}$ Unit of Nephrology, Azienda Ospedaliera "Ospedali Riuniti di Bergamo"; ${ }^{3}$ Mario Negri Institute for Pharmacological Research, Bergamo; ${ }^{4}$ Department of Clinical Science, Sapienza University, Roma; and ${ }^{5}$ Dialysis Unit Simone Martini, Milan, Italy.

* M.C. and G.G. contributed equally to this work.

Received November 2, 2012. Accepted in revised form February 25, 2013.

Address correspondence to Mario Cozzolino, MD, PhD, DMCO, University of Milan, Renal Division, San Paolo Hospital, Via di Rudini 8, 20142 Milan, Italy.E-mail: mario.cozzolino@unimi.it (C) 2013 by the National Kidney Foundation, Inc. 0272-6386/\$36.00

http://dx.doi.org/10.1053/j.ajkd.2013.02.379 
sion) in light of recent findings from experimental and interventional studies.

\section{BLOOD PRESSURE: THE FIRST “P” FOR CKD PROGRESSION}

Hypertension, the leading cause of death worldwide, ${ }^{8}$ may be either a consequence or a cause of $\mathrm{CKD}^{9}$ and is a major independent risk factor for both kidney disease and faster rate of GFR loss. ${ }^{10,11} \mathrm{An}$ increased risk of ESRD beginning at the third quintile of systolic and diastolic blood pressure $(127 / 82 \mathrm{~mm}$ $\mathrm{Hg}$ ) was evident in 332,544 middle-aged men in the Multiple Risk Factor Intervention Trial (MRFIT), ${ }^{10}$ and blood pressure values higher than high normal were associated with a progressive increase in risk of ESRD in the Okinawa mass screening program $(\mathrm{n}=$ 98,759). ${ }^{11}$ There is a large body of evidence that blood pressure reduction may slow GFR loss and reduce cardiovascular outcomes. ${ }^{12}$ However, 2 crucial issues in the management of hypertension in patients with CKD are first, whether a specific blood pressure target may maximize renoprotection, and second, whether a specific drug may be beneficial, independent of blood pressure control. Concerning blood pressure targets, few randomized trials ${ }^{13-16}$ have been conducted in patients with CKD to confirm the association of findings from these cohort studies. ${ }^{10,11}$ In the Modification of Diet in Renal Disease (MDRD) Study, the largest randomized prospective trial performed to date (840 patients, mostly with nondiabetic kidney disease), tight blood pressure control (mean arterial pressure $\leq 92 \mathrm{~mm} \mathrm{Hg}$; ie, blood pressure, $125 / 75 \mathrm{~mm} \mathrm{Hg}$ ) did not improve the primary outcome of GFR reduction, doubling of serum creatinine level, or ESRD. ${ }^{13}$ However, intensive control slowed the progression of CKD when protein excretion $>1 \mathrm{~g} / \mathrm{d},{ }^{17}$ although the greater benefits in GFR decline in these patients may be explained in part by the greater use of angiotensin-converting enzyme (ACE) inhibitors. Similarly, a lower blood pressure goal did not significantly reduce the rate of the composite outcome (GFR reduction $\geq 50 \%$, ESRD, or death) or the mean GFR slope in 1,094 African American hypertensive patients with mild to moderate CKD from the African American Study of Kidney Disease and Hypertension (AASK), ${ }^{15}$ although a trend favoring the lower blood pressure target again was evident in the subgroup with a urinary protein-creatinine ratio $>0.22 \mathrm{~g} / \mathrm{g}$ at baseline (urinary protein excretion $>300 \mathrm{mg} / \mathrm{d}$ ).

In AASK, the ACE inhibitor ramipril afforded 22\% and $38 \%$ greater reductions in the composite outcome compared to metoprolol and amlodipine, respectively. However, the REIN-2 Study highlights that achieving intensive blood pressure control by add-on therapy with the dihydropyridine calcium channel blocker felodipine on top of ramipril was not beneficial in patients with nondiabetic kidney disease, probably because tighter blood pressure control was not accompanied by a reduction in intraglomerular pressure and proteinuria. ${ }^{16}$ Thus, renin-angiotensin-aldosterone system (RAAS)-blocking agents appear to be the key component of renoprotective therapy rather than tight blood pressure control because lowering blood pressure to $<130 / 80 \mathrm{~mm} \mathrm{Hg}$ does not offer additional renoprotection when achieved with drugs not affecting the RAAS or in patients without significant proteinuria or diabetes. ${ }^{18}$ The antiproteinuric properties of RAAS-blocking agents were discovered first by Anderson et $\mathrm{al}^{19}$ and originally attributed to the hemodynamic effects of reduced intraglomerular pressure through preferential dilation of kidney arterioles. More recently, evidence has been provided that RAASblocking agents also ameliorate glomerular sieving function by directly restoring slit diaphragm integrity and increasing negative charge on the glomerular membrane. ${ }^{20}$ After the landmark trial on the use of captopril in diabetic kidney disease conducted by the Collaborative Study Group, ${ }^{21}$ several clinical trials demonstrated that RAAS-blocking agents may effectively maximize reno- and cardioprotection ${ }^{5,22}$ in both diabetic and nondiabetic nephropathies. ${ }^{23-30}$

\section{PROTEINURIA: THE SECOND “P” FOR CKD PROGRESSION}

In healthy adults, urinary protein excretion does not exceed $150 \mathrm{mg} / \mathrm{d} .{ }^{31}$ Until recently, for patients with proteinuria, protein excretion $<1 \mathrm{~g} / \mathrm{d}$ was considered an optimal clinical target due to the low rate of progression toward kidney failure. ${ }^{32}$

More recently, levels of proteinuria as low as protein excretion of $150-500 \mathrm{mg} / \mathrm{d}$ are regarded as a risk factor for progression of kidney disease ${ }^{33}$ and cardiovascular mortality. ${ }^{22,34}$ Both epidemiologic ${ }^{31,35-37}$ and interventional studies ${ }^{6,15,17}$ consistently show a strong and independent association between increasing values of proteinuria and the risk of progression of kidney disease in both diabetic and nondiabetic patients. Proteinuria was the most powerful predictor of ESRD in a general population screening of more than 100,000 Japanese individuals followed up for 10 years. ${ }^{35}$ This strong and graded relationship also was evident for mild increases in protein excretion on dipstick urinalysis. Similar results were evident in a post hoc observational analysis of MRFIT. Dipstick proteinuria with protein excretion of $1+$ or $\geq 2+$ was associated with a greater risk of ESRD over 25 years of follow-up (hazard ratios of 3.1 and 15.7, respectively). ${ }^{37}$ Moreover, high-normal values of urinary albumin excretion were associated independently with the onset of microalbuminuria or decreased kidney 
function in 4,031 patients with type 2 diabetes and normoalbuminuria from the UK Prospective Diabetes Study (UKPDS 74). ${ }^{38}$ Finally, a relationship between higher baseline proteinuria and faster reduction in GFR was found in the MDRD Study, as well as the AASK and REIN trials. ${ }^{6,15,17}$ The latter study also demonstrated that residual proteinuria reliably predicted long-term kidney prognosis regardless of blood pressure control and treatment randomization and independent of initial values of proteinuria and its reduction during follow-up. ${ }^{39}$

Proteinuria also is a strong predictor of cardiovascular risk ${ }^{40,41}$ independent of level of kidney function. ${ }^{3,42}$ In a meta-analysis of 10 cohorts involving 266,975 people at increased risk of CKD, lower GFR and higher albuminuria predicted cardiovascular disease and all-cause mortality independently of each other. ${ }^{43}$ This independent association between any level of proteinuria and total or cardiovascular mortality was confirmed in more than 1.1 million people with proteinuria identified only by detection of "trace" or greater levels following dipstick analysis ${ }^{34}$ and in more than 100,000 individuals with an albumincreatinine ratio $\geq 10 \mathrm{mg} / \mathrm{g} .{ }^{22}$ In light of these findings, all attempts have been made to reduce proteinuria by any therapeutic means, including RAAS-blocking agents, low salt intake, ${ }^{44}$ smoking cessation, optimal metabolic control, and 3-hydroxy-3-methylglutaryl coenzyme A reductase inhibitors. ${ }^{45}$ Multiple therapies aimed at reducing proteinuria may slow the progression of kidney disease to a greater extent than any single treatment. This was demonstrated effectively by a multimodal intervention strategy, the Remission Clinic program, that used all available lifestyle recommendations and pharmacologic tools to further reduce proteinuria in patients with CKD and severe proteinuria already treated with RAAS-blocking agents. ${ }^{46-47}$ We recently confirmed the beneficial effects of this strategy in patients with Alport syndrome. ${ }^{48}$

\section{PHOSPHATE: THE THIRD “P” FOR CKD PROGRESSION}

Seminal observations by Ibels et $\mathrm{al}^{49}$ showed that dietary phosphate restriction prevented proteinuria, kidney calcifications, histologic changes, functional deterioration, and deaths in a murine remnant-kidney model. These findings were confirmed later in patients with CKD treated with a low-phosphorus lownitrogen diet. ${ }^{50}$ A recent post hoc analysis of the REIN Study has further expanded the role of phosphate in CKD progression. ${ }^{51}$ The study had a dual objective: (1) assess the relationship between phosphate levels at inclusion and the incidence of kidney events, and (2) assess whether the protective effect conferred by ramipril on disease progression could be altered by serum phosphate levels. The authors observed that an increase of only $1 \mathrm{mg} / \mathrm{dL}$ in serum phosphate level, irrespective of other risk factors, was associated with an $85 \%$ increase in risk of progression to ESRD. Moreover, patients in higher quartiles of serum phosphate levels showed a significantly lower protective effect from ACE-inhibitor therapy. In patients with serum phosphate levels $>4.5 \mathrm{mg} / \mathrm{dL}$, ACE-inhibitor therapy brought almost no benefit. The interactions observed between serum phosphate level, ACE inhibition, and GFR loss did not change appreciably after adjustment for potential confounders, pointing to a specific pathogenic role for this metabolic imbalance in the progression of CKD.

\section{CROSS-TALK AMONG THE 3 "PS" IN THE PATHOGENESIS OF CKD PROGRESSION: WHAT IS ALREADY KNOWN}

Dysregulation of phosphate homeostasis may ensue in early stages of CKD long before an increase in serum phosphorus levels. Although phosphate homeostasis previously was thought to be regulated exclusively by 1,25 -dihydroxyvitamin $\mathrm{D}_{3}$ (calcitriol) and parathyroid hormone, the FGF-23/klotho system is now considered the main phosphate-regulating endocrine axis. ${ }^{52}$ In the remnant-kidney model of CKD progression, ${ }^{27}$ surviving nephrons must excrete an increasing amount of phosphate to maintain normal phosphate levels. This issue is exacerbated further by high dietary phosphate intake, with phosphate bioavailability playing a central role. ${ }^{53-55}$ Prolonged phosphate load, rather than plasma levels, has been shown to increase serum FGF-23 levels in nephrectomized rats, ${ }^{56}$ suggesting that circulating phosphorus may not adequately reflect phosphorus balance. Through FGF23-mediated mechanisms, phosphorus also may have an inhibitory effect on the production of nitric oxide, ${ }^{57}$ which could reduce or prevent the beneficial effects mediated by nitric oxide activation during ACE-inhibitor therapy. However, the molecular mechanisms underlying the association between prolonged phosphate load and increased levels of FGF23 , which is secreted mainly by bone cells, ${ }^{58}$ are largely unknown. The responsiveness of FGF-23 to dietary phosphate is sluggish (hours to days), ${ }^{59}$ and phosphate does not directly stimulate FGF-23 expression in osteoblast cultures, ${ }^{60}$ emphasizing the importance of other local or systemic regulators. ${ }^{61}$ Higher FGF-23 levels increase urinary phosphate excretion by suppressing the expression of the sodium-dependent phosphate cotransporters NPT2a and NPT2c in the kidney proximal tubule ${ }^{61}$ and reduce phosphorus absorption in the gut by decreasing calcitriol levels. Unfortunately, lower calcitriol levels also stimulate the RAAS through increased renin production and the 


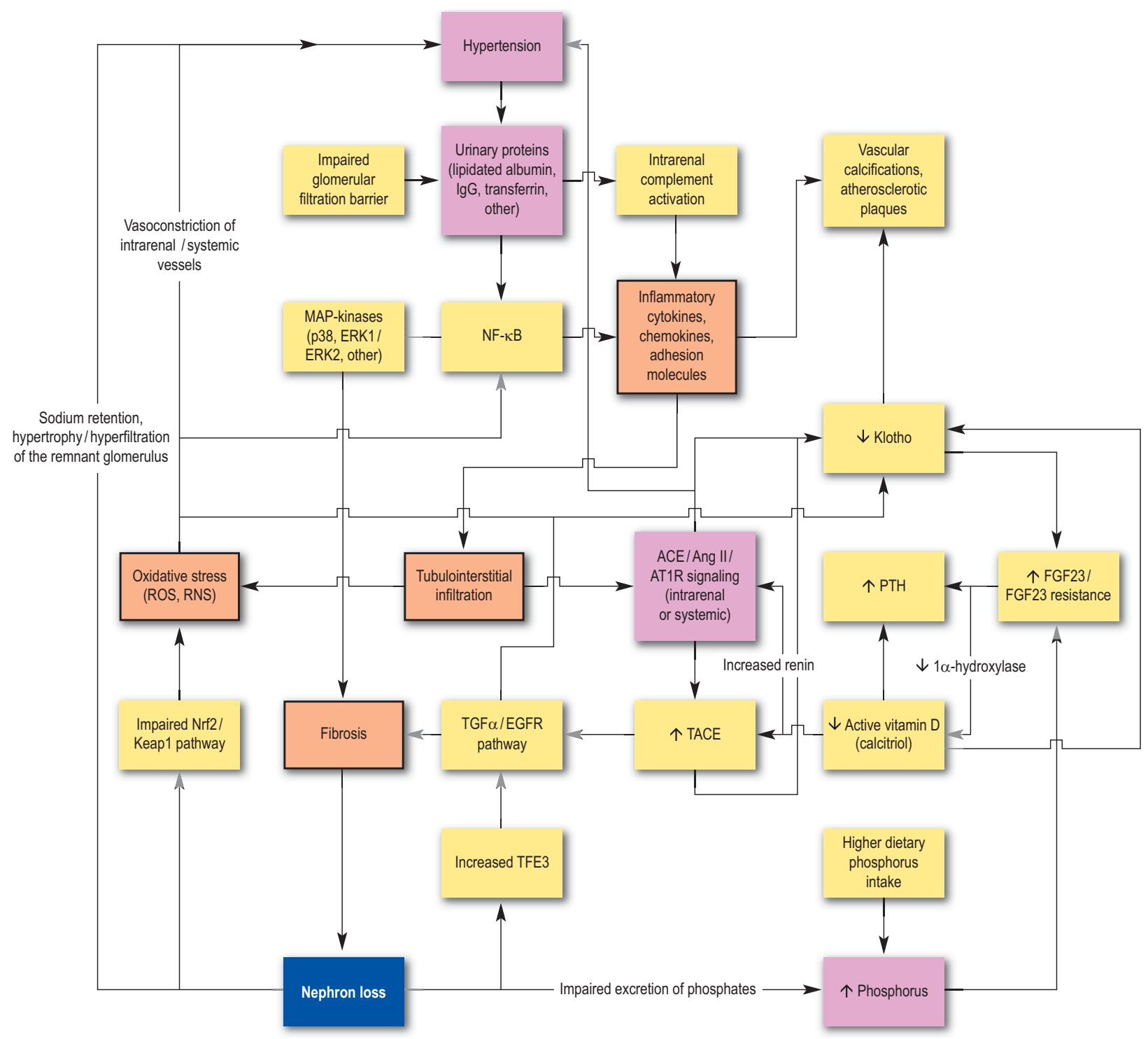

Figure 1. Pathogenesis of chronic kidney disease (hyperglycemia-induced pathways are not shown). Abbreviations: ACE, angiotensin-converting enzyme; Ang II, angiotensin II; AT1R, angiotensin II type 1 receptor; EGFR, epidermal growth factor receptor; FGF, fibroblast growth factor; IgG, immunoglobulin G; MAP, mean arterial pressure; NF- $\kappa$ B, nuclear factor $\kappa$ B; PTH, parathyroid hormone; ROS, reactive oxygen species; RNS, reactive nitrogen species; TACE, tumor necrosis factor $\alpha$-converting enzyme; TFE3, transcription factor E3; TGF, transforming growth factor.

transforming growth factor $\alpha$ (TGF- $\alpha$ )-converting enzyme/TGF- $\alpha$ /epidermal growth factor (EGF) receptor pathway (Fig 1), leading to an increase in inflammation, urinary protein excretion, and fibrosis. This ultimately accelerates the progression of kidney damage and increases the risk of cardiovascular events. ${ }^{62-65}$ FGF-23 also exhibits direct end-organ toxicity on the myocardium and may be involved in the pathogenesis of left ventricular hypertrophy and uremic cardiomyopathy. ${ }^{66}$ Lower calcitriol levels also increase parathyroid hormone secretion, which in turn stimulates FGF-23 synthesis ${ }^{67}$ and TGF- $\alpha$ secretion, ${ }^{68}$ thus generating another vicious circle that could explain in part the increased cardiovascular morbidity and allcause mortality found in patients with $\mathrm{CKD}^{3}$ (Fig 1).

The membrane protein klotho is expressed predominantly in kidney and brain and is recognized to have antiaging properties by preventing atherosclerosis plaques and vascular calcifications. Klotho acts as the necessary cofactor for FGF-23 by forming complexes with the FGF receptors and increasing their affinity for FGF-23. The importance of klotho in FGF-23 signaling is supported because its downregulation by angiotensin II, TGF- $\alpha$-converting enzyme, oxidative stress, nuclear factor $\kappa \mathrm{B}$, and uremic secondary hyperparathyroidism ${ }^{64,69}$ results 
in end-organ resistance to FGF-23 and increased FGF-23 levels. The latter reduces calcitriol levels and further activates the RAAS. Of note, restoration of klotho by gene transfer improves angiotensin II-induced proteinuria. ${ }^{70}$

As this discussion attests, the FGF-23/klotho system is strongly connected with the RAAS (Fig 1). Abnormal activation of the systemic and local RAAS is found commonly in patients with CKD and deeply influences medium- to long-term control of both blood pressure and proteinuria. Among its well-known hemodynamic and nonhemodynamic detrimental effects, angiotensin II also activates the TGF- $\alpha$-converting enzyme/TGF- $\alpha /$ EGF receptor pathway, ${ }^{71}$ which may exacerbate proteinuria and kidney fibrosis. This may occur through the release of proinflammatory and profibrotic cytokines, ${ }^{72}$ including adhesion molecules, ${ }^{73,74}$ and reduced vitamin $\mathrm{D}$ receptor cellsurface expression. ${ }^{68}$

The cross-talk between phosphorus metabolism, the FGF-23/klotho system, and the RAAS may contribute to the initiation and progression of chronic proteinuric nephropathies that are characterized by a loss of selectivity of the glomerular filtration barrier. In this respect, a recent study highlighted the key role of podocyte detachment and the loss of normal endothelial cell fenestration in 37 patients with type 2 diabetes undergoing kidney biopsy. The percentage of podocyte detachment correlated positively with urinary albumin excretion and negatively with number of podocytes per glomerulus. The percentage of endothelial cell fenestration was associated negatively with glomerular basement membrane width and fractional interstitial and mesangial area and positively with filtration surface area density and GFR. Increasing podocyte detachment is associated with decreased permselectivity of the glomerulus and progressive albuminuria, whereas loss of endothelial cell fenestration is associated with GFR decline. ${ }^{75}$ These findings are supportive of previous research in the same field, ${ }^{76}$ recapitulated in a recent review. ${ }^{77}$ Higher levels of proteinuria may increase the release of profibrotic, proinflammatory, and vasoactive molecules ${ }^{78-82}$ with consequent oxidative stress, tubulointerstitial fibrosis, and loss of functional nephrons (Fig 1). ${ }^{83}$ These changes cause further nephron injury, increased intraglomerular pressure, impaired filter function, and further loss of proteins in urine, with concomitant activation of the complement cascade. ${ }^{27,84-86}$ Progressive nephron loss also causes severe impairment of the Nrf2-Keap1 (nuclear factor erythroid 2-related factor 2/kelch-like ECH-associated protein 1) pathway, with increased oxidative stress and inflammation. ${ }^{87,88}$ Inflammation and oxidative stress are linked inseparably and represent major media- tors of CKD progression and the associated cardiovascular complications..$^{62,70,81,89}$

\section{INSIGHTS FROM RECENT EXPERIMENTAL STUDIES AND NOVEL THERAPEUTIC TARGETS}

In patients with $C K D$, the vicious cycle between phosphorus metabolism, the FGF-23/klotho axis, and the RAAS likely is activated even in the presence of serum phosphate levels within the normal range. Dietary phosphate restriction can significantly lower FGF-23 levels ${ }^{53-55}$ and could be more effective if started before serum phosphate levels increase. Vitamin $\mathrm{D}$ receptor agonists may effectively inhibit both the TGF- $\alpha$-converting enzyme/TGF $\alpha /$ EGF receptor pathway and the RAAS in the parathyroid and kidney ${ }^{90,91}$ and reduce vascular calcification, podocyte damage, ${ }^{63,92-94}$ and proteinuria through blockade of $\mathrm{Wnt} / \beta$-catenin signaling. ${ }^{95}$ Vitamin $\mathrm{D}$ receptor agonists also may upregulate klotho ${ }^{96}$ and exert an antiinflammatory action through the reduction of nuclear factor $\kappa \mathrm{B}$. These actions may explain in part the nephroprotective effects and reduced mortality observed in patients treated with vitamin D receptor agonists independent of serum 25-dehydroxyvitamin D levels. ${ }^{97-101}$ Non-calcium-based phosphate binders may correct hyperphosphatemia and ameliorate abnormalities of the mineral metabolism associated with accelerated kidney disease progression and increased cardiovascular risk. ${ }^{102-104}$ The finding that phosphate binders reduced proteinuria, an effect that appears to be associated with significant renoprotection in the long term according to recent animal studies (Fig 2), ${ }^{105,106}$ along with results of the post hoc analysis of the REIN Study, ${ }^{51}$ can be taken to suggest that strategies aimed at lowering phosphate levels might be used in the future to maximize the renoprotective effects of RAAS-blocking agents.

\section{FUTURE PERSPECTIVES}

In summary, the complex interactions among the different pathways of CKD progression may explain why the specific renoprotective effects of traditional RAAS-blocking agents are blunted by serum phosphate levels $>4.5 \mathrm{mg} / \mathrm{dL}$. This is a major issue because RAAS inhibition currently is the standard therapy for proteinuric nephropathies. In particular, there is a need for additional randomized controlled trials with longer follow-up and hard kidney end points to evaluate the hypothesis that additional therapeutic interventions may be instrumental to improving renoprotection in this high-risk population. In this respect, an ongoing trial will evaluate the renoprotective effects of serum phosphate reduction by noncalcium phosphate binders in patients with CKD with 


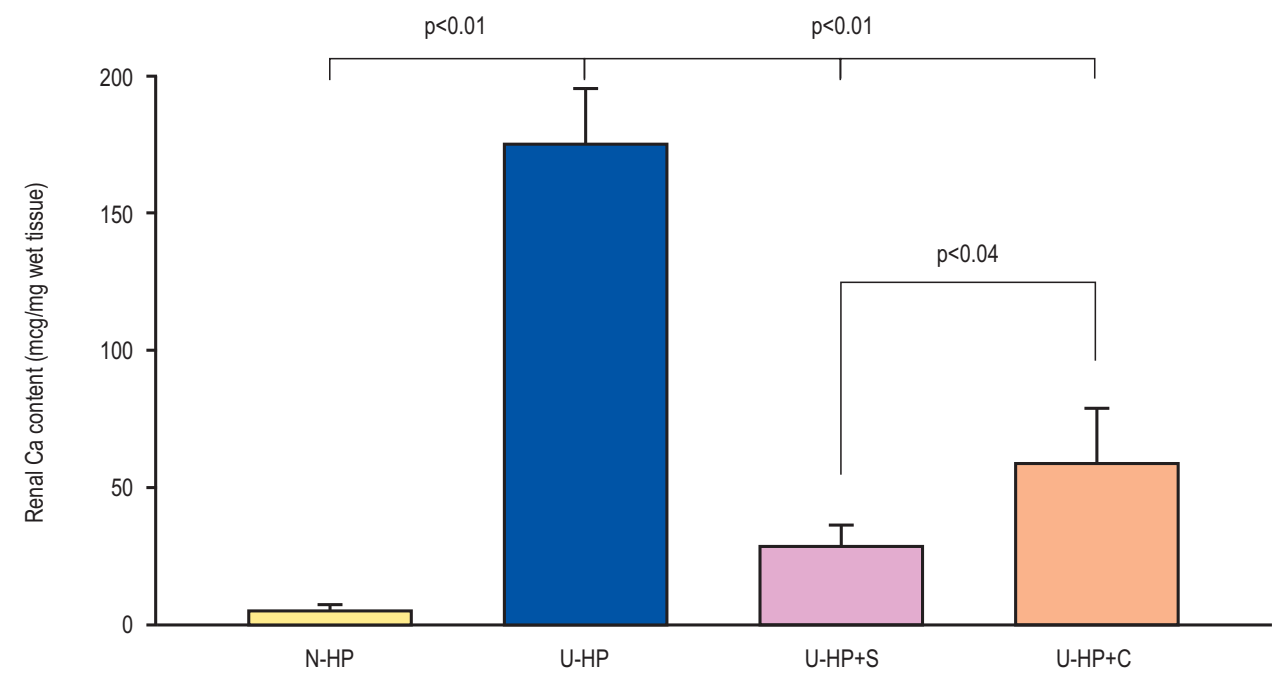

Figure 2. Effects of sevelamer and calcium carbonate on kidney calcium content. Kidney calcium deposition in normal and uremic (5/6-nephrectomized) rats undergoing one of the following experimental protocols for 3 months: (1) normal plus high-phosphorus diet (N-HP); (2) uremic control plus HP diet (U-HP); (3) U-HP plus 3\% sevelamer (U-HP+S); and (4) U-HP plus 3\% calcium carbonate $(\mathrm{U}-\mathrm{HP}+\mathrm{C})$. Data presented as mean \pm standard error, mean from 7 rats. $P$ values indicate statistically significant differences between groups (analysis of variance followed by Bonferroni post hoc). Adapted from Cozzolino et al ${ }^{106}$ with permission of the American Society of Nephrology.

reference serum phosphate levels and residual proteinuria despite optimal RAAS-inhibitor therapy according to the Remission Clinic approach.

\section{ACKNOWLEDGEMENTS}

The authors thank Dr Colin G. Egan (Primula Multimedia, SRL, Pisa Italy) for assistance in revising the manuscript.

Support: None.

Financial Disclosure: The authors declare that they have no relevant financial interests.

\section{REFERENCES}

1. Couser WG, Remuzzi G, Mendis S, Tonelli M. The contribution of chronic kidney disease to the global burden of major noncommunicable diseases. Kidney Int. 2011;80(12):1258-1270.

2. International Society of Nephrology. A briefing on the global impact of kidney disease. 2011. http://www.theisn.org/images/ stories/WHO_CKD_Brochure_LR.pdf. Accessed February 15, 2013.

3. Go AS, Chertow GM, Fan D, McCulloch CE, Hsu CY. Chronic kidney disease and the risks of death, cardiovascular events, and hospitalization. N Engl J Med. 2004;351(31):12961305.

4. Wuhl E, Schaefer F; Medscape. Managing kidney disease with blood-pressure control. Nat Rev Nephrol. 2011;7(8):434-444.

5. Rahman M, Pressel S, Davis BR, et al. Cardiovascular outcomes in high-risk hypertensive patients stratified by baseline glomerular filtration rate. Ann Intern Med. 2006;144(3):72-180.

6. Ruggenenti P, Perna A, Mosconi L, Pisoni R, Remuzzi G. Urinary protein excretion rate is the best independent predictor of ESRF in non-diabetic proteinuric chronic nephropathies. "Gruppo Italiano di Studi Epidemiologici in Nefrologia" (GISEN). Kidney Int. 1998;53(5):1209-1216.

7. de Zeeuw D, Remuzzi G, Parving HH, et al. Albuminuria, a therapeutic target for cardiovascular protection in type 2 diabetic patients with nephropathy. Circulation. 2004;110(8):921-927.
8. World Health Organization. Global health risks: mortality and burden of disease attributable to selected major risks. 2009. http://www.who.int/healthinfo/global_burden_disease/GlobalHealth Risks_report_part2.pdf. Accessed February 15, 2013.

9. Paul M, Poyan Mehr A, Kreutz R. Physiology of local renin-angiotensin systems. Physiol Rev. 2006;86(3):747-803.

10. Klag MJ, Whelton PK, Randall BL, et al. Blood pressure and end-stage renal disease in men. N Engl J Med. 1996;334(1):13-18.

11. Tozawa M, Iseki K, Iseki C, Kinjo K, Ikemiya Y, Takishita S. Blood pressure predicts risk of developing end-stage renal disease in men and women. Hypertension. 2003;41(6): 1341-1345.

12. Cravedi P, Ruggenenti P, Remuzzi G. Which antihypertensive drugs are the most nephroprotective and why? Expert Opin Pharmacother. 2010;11(16):2651-2663.

13. Klahr S, Levey AS, Beck GJ, et al. The effects of dietary protein restriction and blood-pressure control on the progression of chronic renal disease. Modification of Diet in Renal Disease Study Group. N Engl J Med. 1994;330(13):877-884.

14. Toto RD, Mitchell HC, Smith RD, Lee HC, McIntire D, Pettinger WA. "Strict" blood pressure control and progression of renal disease in hypertensive nephrosclerosis. Kidney Int. 1995; 48(3): 851-859.

15. Wright JT, Bakris G, Greene T, et al. Effect of blood pressure lowering and antihypertensive drug class on progression of hypertensive kidney disease: results from the AASK trial. JAMA. 2002;288(19):2421-2431.

16. Ruggenenti P, Perna A, Loriga G, et al. Blood-pressure control for renoprotection in patients with non-diabetic chronic renal disease (REIN-2): multicentre, randomised controlled trial. Lancet. 2005;365(9463):939-946.

17. Peterson JC, Adler S, Burkart JM, et al. Blood pressure control, proteinuria, and the progression of renal disease. The Modification of Diet in Renal Disease Study. Ann Intern Med. 1995;123(10):754-762.

18. British Renal Association Society Guidelines. Detection, monitoring and care of patients with CKD. 2011. http://www.rena1.org/Clinical/GuidelinesSection/Detection-Monitoring-and-Careof-Patients-with-CKD.aspx. Accessed February 15, 2013. 
19. Anderson S, Meyer TW, Rennke HG, Brenner BM. Control of glomerular hypertension limits glomerular injury in rats with reduced renal mass. J Clin Invest. 1985;76(2):612-619.

20. Deyneli O, Yavuz D, Velioglu A, et al. Effects of ACE inhibition and angiotensin II receptor blockade on glomerular basement membrane protein excretion and charge selectivity in type 2 diabetic patients. J Renin Angiotensin Aldosterone Syst. 2006;7(2):98-103.

21. Lewis EJ, Hunsicker LG, Bain RP, Rohde RD. The effect of angiotensin-converting-enzyme inhibition on diabetic nephropathy. The Collaborative Study Group. N Engl J Med. 1993;329(20): 1456-1462.

22. Matsushita K, van der Velde M, Astor BC, et al. Association of estimated glomerular filtration rate and albuminuria with allcause and cardiovascular mortality in general population cohorts: a collaborative meta-analysis. Lancet. 2010;375(9731):2073-2081.

23. Randomised placebo-controlled trial of effect of ramipril on decline in glomerular filtration rate and risk of terminal renal failure in proteinuric, non-diabetic nephropathy. The GISEN Group (Gruppo Italiano di Studi Epidemiologici in Nefrologia). Lancet. 1997;349(9069):1857-1863.

24. Hovind P, Rossing P, Tarnow L, Toft H, Parving J, Parving HH. Remission of nephrotic-range albuminuria in type 1 diabetic patients. Diabetes Care. 2001;24(11):1972-1977.

25. Atkins RC, Briganti EM, Lewis JB, et al. Proteinuria reduction and progression to renal failure in patients with type 2 diabetes mellitus and overt nephropathy. Am J Kidney Dis. 2005; 45(2):281-287.

26. Keane WF, Zhang Z, Lyle PA, et al. Risk scores for predicting outcomes in patients with type 2 diabetes and nephropathy: the RENAAL Study. Clin J Am Soc Nephrol. 2006;1(4):761767.

27. Remuzzi G, Benigni A, Remuzzi A. Mechanisms of progression and regression of renal lesions of chronic nephropathies and diabetes. J Clin Invest. 2006;116(2):288-296.

28. Parving HH, Lehnert H, Brochner-Mortensen J, Gomis R, Andersen S, Arner P. The effect of irbesartan on the development of diabetic nephropathy in patients with type 2 diabetes. $N$ Engl J Med. 2001;345(12):870-878.

29. Brenner BM, Cooper ME, de Zeeuw D, et al. Effects of losartan on renal and cardiovascular outcomes in patients with type 2 diabetes and nephropathy. N Engl J Med. 2001;345(12):861-869.

30. Maschio G, Alberti D, Janin G, et al. Effect of the angiotensin-converting-enzyme inhibitor benazepril on the progression of chronic renal insufficiency. The Angiotensin-Converting-Enzyme Inhibition in Progressive Renal Insufficiency Study Group. N Engl J Med. 1996;334(15):939-945.

31. Cravedi P, Ruggenenti P, Remuzzi G. Proteinuria should be used as a surrogate in CKD. Nat Rev Nephrol. 2012;8(5):301-306.

32. Remuzzi G, Ruggenenti P, Benigni A. Understanding the nature of renal disease progression. Kidney Int. 1997;51(1):2-15.

33. Levey AS, de Jong PE, Coresh J, et al. The definition, classification, and prognosis of chronic kidney disease: a KDIGO Controversies Conference report. Kidney Int. 2011;80 (1):17-28.

34. Chronic Kidney Disease Prognosis Consortium. Association of estimated glomerular filtration rate and albuminuria with all-cause and cardiovascular mortality in general population cohorts: a collaborative meta-analysis. Lancet. 2010;375(9731):20732081.

35. Iseki K, Iseki C, Ikemiya Y, Fukiyama K. Risk of developing end-stage renal disease in a cohort of mass screening. Kidney Int. 1996;49(3):800-805.

36. Iseki K, Ikemiya Y, Iseki C, Takishita S. Proteinuria and the risk of developing end-stage renal disease. Kidney Int. 2003;63(4): 1468-1474.
37. Ishani A, Grandits GA, Grimm RH, et al. Association of single measurements of dipstick proteinuria, estimated glomerular filtration rate, and hematocrit with 25-year incidence of end-stage renal disease in the Multiple Risk Factor Intervention Trial. $J$ Am Soc Nephrol. 2006;17(5):1444-1452.

38. Retnakaran R, Cull CA, Thorne KI, Adler AI, Holman RR; UKPDS Study Group. Risk factors for renal dysfunction in type 2 diabetes: U.K. Prospective Diabetes Study 74. Diabetes. 2006; 55(6): 1832-1839.

39. Ruggenenti P, Perna A, Remuzzi G; GISEN Group Investigators. Retarding progression of chronic renal disease: the neglected issue of residual proteinuria. Kidney Int. 2003;63(6):22542261.

40. Ninomiya T, Perkovic V, Verdon C, et al. Proteinuria and stroke: a meta-analysis of cohort studies. Am J Kidney Dis. 2009;53(3):417-425.

41. Bello AK, Hemmelgarn B, Lloyd A, et al. Associations among estimated glomerular filtration rate, proteinuria, and adverse cardiovascular outcomes. Clin J Am Soc Nephrol. 2011;6(6): 1418-1426.

42. Hallan SI, Ritz E, Lydersen S, Romundstad S, Kvenild K, Orth SR. Combining GFR and albuminuria to classify CKD improves prediction of ESRD. J Am Soc Nephrol. 2009;20(5):10691077.

43. van der Velde M, Matsushita K, Coresh J, et al. Lower estimated glomerular filtration rate and higher albuminuria are associated with all-cause and cardiovascular mortality. A collaborative meta-analysis of high-risk population cohorts. Kidney Int. 2011;79(12):1341-1352.

44. Myrvang $\mathrm{H}$. Progression of renal disease: high salt intake blunts the benefit of ACE inhibitors and accelerates renal function decline. Nat Rev Nephrol. 2012;8(2):61.

45. Ruggenenti P, Perna A, Tonelli M, et al. Effects of add-on fluvastatin therapy in patients with chronic proteinuric nephropathy on dual renin-angiotensin system blockade: the ESPLANADE trial. Clin J Am Soc Nephrol. 2010;5(11):1928-1938.

46. Zoja C, Corna D, Camozzi D, et al. How to fully protect the kidney in a severe model of progressive nephropathy: a multidrug approach. J Am Soc Nephrol. 2002;13(12):2898-2908.

47. Ruggenenti P, Perticucci E, Cravedi P, et al. Role of remission clinics in the longitudinal treatment of CKD. J Am Soc Nephrol. 2008;19(6):1213-1224.

48. Daina E, Gamba S, Ruggenenti P, et al. Effects of the remission clinic approach in Alport syndrome: results from a prospective, sequential cohort study. American Society of Nephrology (ASN) Kidney Week. 2012. https://www.asn-online.org/scripts/ download.aspx?file=/education/kidneyweek/archives/KW12 Abstracts.pdf. Accessed February 15, 2013.

49. Ibels LS, Alfrey AC, Haut L, Huffer WE. Preservation of function in experimental renal disease by dietary restriction of phosphate. N Engl J Med. 1978;298(3):122-126.

50. Barsotti G, Morelli E, Giannoni A, Guiducci A, Lupetti S, Giovannetti S. Restricted phosphorus and nitrogen intake to slow the progression of chronic renal failure: a controlled trial. Kidney Int Suppl. 1983;16:S278-S284.

51. Zoccali C, Ruggenenti P, Perna A, et al. Phosphate may promote CKD progression and attenuate renoprotective effect of ACE inhibition. J Am Soc Nephrol. 2011;22(10):1923-1930.

52. John GB, Cheng CY, Kuro-o M. Role of klotho in aging, phosphate metabolism, and CKD. Am J Kidney Dis. 2011;58(1): 127-134.

53. Uribarri J, Calvo MS. Hidden sources of phosphorus in the typical American diet: does it matter in nephrology? Semin Dial. 2003;16(3):186-188.

54. Isakova T, Gutierrez OM, Smith K, et al. Pilot study of dietary phosphorus restriction and phosphorus binders to target 
fibroblast growth factor 23 in patients with chronic kidney disease. Nephrol Dial Transplant. 2011;26(2):584-591.

55. Moe SM, Zidehsarai MP, Chambers MA, et al. Vegetarian compared with meat dietary protein source and phosphorus homeostasis in chronic kidney disease. Clin J Am Soc Nephrol. 2011;6(2): 257-264.

56. Saito H, Maeda A, Ohtomo S, et al. Circulating FGF-23 is regulated by 1alpha,25-dihydroxyvitamin $\mathrm{D}_{3}$ and phosphorus in vivo. J Biol Chem. 2005;80(4):2543-2549.

57. Shuto E, Taketani Y, Tanaka R, et al. Dietary phosphorus acutely impairs endothelial function. J Am Soc Nephrol. 2009;20(7): 1504-1512.

58. Martin A, David V, Quarles LD. Regulation and function of the FGF23/klotho endocrine pathways. Physiol Rev. 2012;92(1): 131-155.

59. Wolf M. Update on fibroblast growth factor 23 in chronic kidney disease. Kidney Int. 2012;82(7):737-747.

60. Liu S, Tang W, Zhou J, et al. Fibroblast growth factor 23 is a counter-regulatory phosphaturic hormone for vitamin D. J Am Soc Nephrol. 2006;17(5):1305-1315.

61. Gattineni J, Bates C, Twombley K, et al. FGF23 decreases renal $\mathrm{NaPi}-2 \mathrm{a}$ and $\mathrm{NaPi}-2 \mathrm{c}$ expression and induces hypophosphatemia in vivo predominantly via FGF receptor 1. Am J Physiol Renal Physiol. 2009:297(2):F282-F291.

62. Yilmaz MI, Sonmez A, Saglam M, et al. FGF-23 and vascular dysfunction in patients with stage 3 and 4 chronic kidney disease. Kidney Int. 2010;78(7):679-685.

63. Li YC, Kong J, Wei M, Chen ZF, Liu SQ, Cao LP. 1,25 -Dihydroxyvitamin $\mathrm{D}(3)$ is a negative endocrine regulator of the renin-angiotensin system. J Clin Invest. 2002;110(2):229-238.

64. De Borst MH, Vervloet MG, Ter Wee PM, Navis G. Cross talk between the renin-angiotensin-aldosterone system and vitamin D-FGF-23-klotho in chronic kidney disease. J Am Soc Nephrol. 2011;22(9):1603-1609.

65. Kendrick J, Cheung AK, Kaufman JS, et al. FGF-23 associates with death, cardiovascular events, and initiation of chronic dialysis. J Am Soc Nephrol. 2011;22(10):1913-1922.

66. Faul C, Amaral AP, Oskouei B, et al. FGF23 induces left ventricular hypertrophy. J Clin Invest. 2011;121(11):4393-4408.

67. Lavi-Moshayoff V, Wasserman G, Meir T, Silver J, NavehMany T. PTH increases FGF23 gene expression and mediates the high-FGF23 levels of experimental kidney failure: a bone parathyroid feedback loop. Am J Physiol Renal Physiol. 2010;299(4):F882F889.

68. Dusso A, Arcidiacono MV, Yang J, Tokumoto M. Vitamin D inhibition of TACE and prevention of renal osteodystrophy and cardiovascular mortality. J Steroid Biochem Mol Biol. 2010;121 (1-2):193-198.

69. Moreno JA, Izquierdo MC, Sanchez-Nino MD, et al. The inflammatory cytokines TWEAK and TNFalpha reduce renal klotho expression through NFkappaB. J Am Soc Nephrol. 2011;22(7):13151325.

70. Mitani H, Ishizaka N, Aizawa T, et al. In vivo klotho gene transfer ameliorates angiotensin II-induced renal damage. Hypertension. 2002;39(4):838-843.

71. Black RA, Rauch CT, Kozlosky CJ, et al. A metalloproteinase disintegrin that releases tumour-necrosis factor-alpha from cells. Nature. 1997;385(6618):729-733.

72. Melenhorst WB, Visser L, Timmer A, van den Heuvel MC, Stegeman CA, van Goor H. ADAM17 upregulation in human renal disease: a role in modulating TGF-alpha availability? Am J Physiol Renal Physiol. 2009;297(3):F781-F790.

73. Dusso A, Gonzalez EA, Martin KJ. Vitamin D in chronic kidney disease. Best Pract Res Clin Endocrinol Metab. 2011;25(4): 647-655.
74. Dusso AS. Renal vitamin D receptor expression and vitamin D renoprotection. Kidney Int. 2012;81(10):937-939.

75. Weil EJ, Lemley KV, Mason CC, et al. Podocyte detachment and reduced glomerular capillary endothelial fenestration promote kidney disease in type 2 diabetic nephropathy. Kidney Int. 2012;82(9):1010-1017.

76. Remuzzi G, Bertani T. Pathophysiology of progressive nephropathies. N Engl J Med. 1998;339(20):1448-1456.

77. Ruggenenti P, Cravedi P, Remuzzi G. Mechanisms and treatment of CKD. J Am Soc Nephrol. 2012;23(12):1917-1928.

78. Zoja C, Morigi M, Figliuzzi M, et al. Proximal tubular cell synthesis and secretion of endothelin-1 on challenge with albumin and other proteins. Am J Kidney Dis. 1995;26(6):934-941.

79. Drumm K, Bauer B, Freudinger R, Gekle M. Albumin induces NF-kappaB expression in human proximal tubule-derived cells (IHKE-1). Cell Physiol Biochem. 2002;12(4):187-196.

80. Tang S, Leung JC, Abe K, et al. Albumin stimulates interleukin-8 expression in proximal tubular epithelial cells in vitro and in vivo. J Clin Invest. 2003;111(4):515-527.

81. Abbate M, Zoja C, Remuzzi G. How does proteinuria cause progressive renal damage? J Am Soc Nephrol. 2006;17(11):29742984.

82. Barnes JL, Gorin Y. Myofibroblast differentiation during fibrosis: role of $\mathrm{NAD}(\mathrm{P}) \mathrm{H}$ oxidases. Kidney Int. 2011;79(9):944956.

83. Johnson DW, Saunders HJ, Baxter RC, Field MJ, Pollock CA. Paracrine stimulation of human renal fibroblasts by proximal tubule cells. Kidney Int. 1998;54(3):747-757.

84. Biancone L, David S, Della Pietra V, Montrucchio G, Cambi V, Camussi G. Alternative pathway activation of complement by cultured human proximal tubular epithelial cells. Kidney Int. 1994;45(2):451-460.

85. Nangaku M, Pippin J, Couser WG. Complement membrane attack complex (C5b-9) mediates interstitial disease in experimental nephrotic syndrome. J Am Soc Nephrol. 1999;10(11):23232331.

86. Rangan GK, Pippin JW, Coombes JD, Couser WG. C5b-9 does not mediate chronic tubulointerstitial disease in the absence of proteinuria. Kidney Int. 2005;67(2):492-503.

87. Kim HJ, Vaziri ND. Contribution of impaired Nrf2-Keap1 pathway to oxidative stress and inflammation in chronic renal failure. Am J Physiol Renal Physiol. 2010;298(3):F662-F671.

88. Laouari D, Burtin M, Phelep A, et al. A transcriptional network underlies susceptibility to kidney disease progression. EMBO Mol Med. 2012;4(8):825-839.

89. Rodriguez-Iturbe B, Vaziri ND, Herrera-Acosta J, Johnson RJ. Oxidative stress, renal infiltration of immune cells, and saltsensitive hypertension: all for one and one for all. Am J Physiol Renal Physiol. 2004;286(4):F606-F616.

90. Cozzolino M, Lu Y, Finch J, Slatopolsky E, Dusso AS. p21WAF1 and TGF-alpha mediate parathyroid growth arrest by vitamin D and high calcium. Kidney Int. 2001;60(6): 2109-2117.

91. Lautrette A, Li S, Alili R, et al. Angiotensin II and EGF receptor cross-talk in chronic kidney diseases: a new therapeutic approach. Nat Med. 2005;11(8):867-874.

92. Xiang W, Kong J, Chen S, et al. Cardiac hypertrophy in vitamin D receptor knockout mice: role of the systemic and cardiac renin-angiotensin systems. Am J Physiol Endocrinol Metab. 2005; 288(1):E125-E132.

93. Bodyak N, Ayus JC, Achinger S, et al. Activated vitamin D attenuates left ventricular abnormalities induced by dietary sodium in Dahl salt-sensitive animals. Proc Natl Acad Sci U S A. 2007; 104(43):16810-16815.

94. Kuhlmann A, Haas CS, Gross ML, et al. 1,25-Dihydroxyvitamin $\mathrm{D}_{3}$ decreases podocyte loss and podocyte hypertrophy in the 
subtotally nephrectomized rat. Am J Physiol Renal Physiol. 2004;286(3):F526-F533.

95. He W, Kang YS, Dai C, Liu Y. Blockade of Wnt/betacatenin signaling by paricalcitol ameliorates proteinuria and kidney injury. J Am Soc Nephrol. 2011;22(1):90-103.

96. Lau WL, Leaf EM, Hu MC, et al. Vitamin D receptor agonists increase klotho and osteopontin while decreasing aortic calcification in mice with chronic kidney disease fed a high phosphate diet. Kidney Int. 2012;82(12):1261-1270.

97. Wolf M, Shah A, Gutierrez O, et al. Vitamin D levels and early mortality among incident hemodialysis patients. Kidney Int. 2007;72(8):1004-1013.

98. de Zeeuw D, Agarwal R, Amdahl M, et al. Selective vitamin $\mathrm{D}$ receptor activation with paricalcitol for reduction of albuminuria in patients with type 2 diabetes (VITAL study): a randomised controlled trial. Lancet. 2010;376(9752):1543-1551.

99. Cheng J, Zhang W, Zhang X, Li X, Chen J. Efficacy and safety of paricalcitol therapy for chronic kidney disease: a metaanalysis. Clin J Am Soc Nephrol. 2012;7(3):391-400.

100. Alborzi P, Patel NA, Peterson C, et al. Paricalcitol reduces albuminuria and inflammation in chronic kidney disease: a randomized double-blind pilot trial. Hypertension. 2008;52(2): 249-255.
101. Fishbane S, Chittineni H, Packman M, Dutka P, Ali N, Durie N. Oral paricalcitol in the treatment of patients with CKD and proteinuria: a randomized trial. Am J Kidney Dis. 2009;54(4): 647-652

102. Block GA, Klassen PS, Lazarus JM, Ofsthun N, Lowrie EG, Chertow GM. Mineral metabolism, mortality, and morbidity in maintenance hemodialysis. J Am Soc Nephrol. 2004;15(8):22082218.

103. Kestenbaum B, Sampson JN, Rudser KD, et al. Serum phosphate levels and mortality risk among people with chronic kidney disease. J Am Soc Nephrol. 2005;16(2):520-528.

104. Ix JH, Shlipak MG, Wassel CL, Whooley MA. Fibroblast growth factor-23 and early decrements in kidney function: the Heart and Soul Study. Nephrol Dial Transplant. 2010;25(3):993997.

105. Cozzolino M, Staniforth ME, Liapis H, et al. Sevelamer hydrochloride attenuates kidney and cardiovascular calcifications in long-term experimental uremia. Kidney Int. 2003;64(5):16531661 .

106. Cozzolino M, Dusso AS, Liapis H, et al. The effects of sevelamer hydrochloride and calcium carbonate on kidney calcification in uremic rats. J Am Soc Nephrol. 2002;13(9):2299-2308. 